\title{
Erector spinae plane block for the management of chronic shoulder pain: a case report
}

\section{Bloc du plan des muscles érecteurs du rachis pour la prise en charge de la douleur chronique à l'épaule : une présentation de cas}

\author{
Mauricio Forero, MD, FIPP • Manikandan Rajarathinam, MD, FIPP • \\ Sanjib Das Adhikary, MD • Ki Jinn Chin, MBBS (Hons), MMed, FRCPC (1)
}

Received: 28 September 2017/ Accepted: 2 November 2017/Published online: 13 November 2017

(C) Canadian Anesthesiologists' Society 2017

\begin{abstract}
Purpose The erector spinae plane (ESP) block has been described in the successful management of both thoracic and abdominal pain. Since the erector spinae muscle extends to the cervical spine, the ESP block may be potentially useful in painful conditions of the shoulder girdle.

Clinical features We performed a series of ESP blocks at the T2/T3 level in an elderly male patient with chronic shoulder pain. Immediate and profound analgesia with improved range of motion was consistently observed following the block. There was detectable sensory block in the congruent cervico-thoracic dermatomes with no motor block. Computed tomography imaging showed the spread of radiocontrast up to the $C 3$ level in the vicinity of the neural foramina. Clinical analgesia generally outlasted the expected duration of conduction blockade and significantly contributed to overall improvement in the patient's symptoms.
\end{abstract}

M. Forero, MD, FIPP

Department of Anesthesia, McMaster University, Hamilton, ON, Canada

M. Rajarathinam, MD, FIPP

Department of Anesthesia, Western University, London, ON, Canada

S. D. Adhikary, MD

Department of Anesthesia, Penn State Hershey Medical Center, Hershey, PA, USA

\section{K. J. Chin, MBBS (Hons), MMed, FRCPC ( $\square$ )}

Department of Anesthesia, University of Toronto, Toronto

Western Hospital, McL 2-405, 399 Bathurst St, Toronto,

ON M5T 2S8, Canada

e-mail: gasgenie@gmail.com
Conclusions The ESP block may be a promising alternative to other interventional procedures in the management of chronic shoulder pain and deserves further study.

\section{Résumé}

Objectif Le bloc du plan des muscles érecteurs du rachis (ou bloc ESP, pour erector spinae plane) a été décrit dans des cas de prise en charge de la douleur thoracique et abdominale. Étant donné que les érecteurs du rachis s'étendent jusqu'à la colonne cervicale, le bloc ESP pourrait être utile en cas de conditions douloureuses au niveau de la ceinture scapulaire.

Éléments cliniques Nous avons réalisé une série de blocs ESP au niveau T2/T3 chez un patient masculin âgé souffrant de douleur chronique à l'épaule. Une analgésie immédiate et profonde, accompagnée d'une amplitude articulaire améliorée, a été observée de manière constante après la réalisation $d u$ bloc. Un bloc sensoriel détectable dans les dermatomes cervico-thoraciques congruents a également été observée et ce, sans bloc moteur. Les images de tomodensitométrie ont montré la diffusion du produit de contraste radiologique jusqu'au niveau C3 à proximité des foramens intervertébraux. L'analgésie clinique a en général duré plus longtemps que la durée pharmacologique prévue du bloc et a considérablement contribué à l'amélioration globale des symptômes du patient.

Conclusion Un bloc ESP pourrait constituer une alternative prometteuse aux autres procédures interventionnelles pour la prise en charge de la douleur chronique à l'épaule, et cette modalité mérite d'être étudiée de manière plus approfondie. 
Chronic shoulder pain is a debilitating condition with significant impact on daily living and working activities and overall quality of life. ${ }^{1}$ Multiple ultrasound (US)guided procedures have been described to treat chronic shoulder pain refractory to conservative management; these generally involve local anesthetic and steroid injections into the bursa, tendons, and joints around the shoulder. $^{2,3}$ The erector spinae plane (ESP) block is a relatively novel US-guided technique that was originally described in the management of thoracic pain when performed at the T5 vertebral level, ${ }^{4-6}$ but has also been successfully applied to abdominal analgesia when performed at the lower levels of T8-10..$^{7-9}$ In this report, we extend this concept by describing the management of chronic shoulder pain with ESP blockade at the T2/T3 vertebral level, together with radiological evidence for the likely mechanism of action.

\section{Case description}

We obtained written informed patient consent for this report. A 73-yr-old male patient was referred to the pain clinic for management of long-standing bilateral shoulder pain. Magnetic resonance imaging had showed a combination of rotator cuff tears, subacromial bursitis, bicipital tendinopathy, and degenerative changes of the acromioclavicular joint in both shoulders. He had declined arthroscopic rotator cuff repair and opted instead for conservative management with physiotherapy and celecoxib $100 \mathrm{mg}$ twice daily as needed. A series of three US-guided right subdeltoid bursa injections with bupivacaine and methylprednisolone at two-month intervals, combined with physiotherapy, improved his right shoulder pain but he subsequently developed excruciating pain in his left shoulder. He described the intensity as $8 / 10$ on a numerical rating scale (NRS), interfering with his sleep, and he was unable to abduct his shoulder beyond $90^{\circ}$. Based on our successful experience with the ESP block in chronic thoracic pain, ${ }^{5}$ we proposed a left ESP block to alleviate his shoulder pain, to which the patient agreed after a discussion of potential risks and benefits.

After establishing intravenous access and applying patient monitors, the patient was placed in a sitting position and a high-frequency linear-array transducer (NextGen LOGIQe; GE Healthcare, Wawautosa, WI, USA) was used to identify the T3 transverse process by counting down from the first rib. The transducer was placed in a longitudinal parasagittal orientation to identify the tip of the transverse process deep to the overlying muscles (Fig. 1A). An 8-cm 22G block needle (EchoStim; Benlan Inc., Oakville, ON, Canada) was inserted in-plane to the US beam in a caudal-to-cranial direction to place the needle tip between the posterior fascia of the erector spinae muscle and the $\mathrm{T} 3$ transverse process. This was verified by hydrodissection with $0.5-1 \mathrm{~mL}$ of normal saline and visualization of linear fluid spread deep to the erector spinae muscle (Fig. 1B), following which $20 \mathrm{~mL}$ of $0.5 \%$ bupivacaine and $40 \mathrm{mg}$ of methylprednisolone was injected.

Within ten minutes, the patient reported complete resolution of pain and had regained full active range of motion in his shoulder, including abduction overhead to $180^{\circ}$. Neurological assessment at $30 \mathrm{~min}$ revealed diminished pinprick sensation over the right neck and

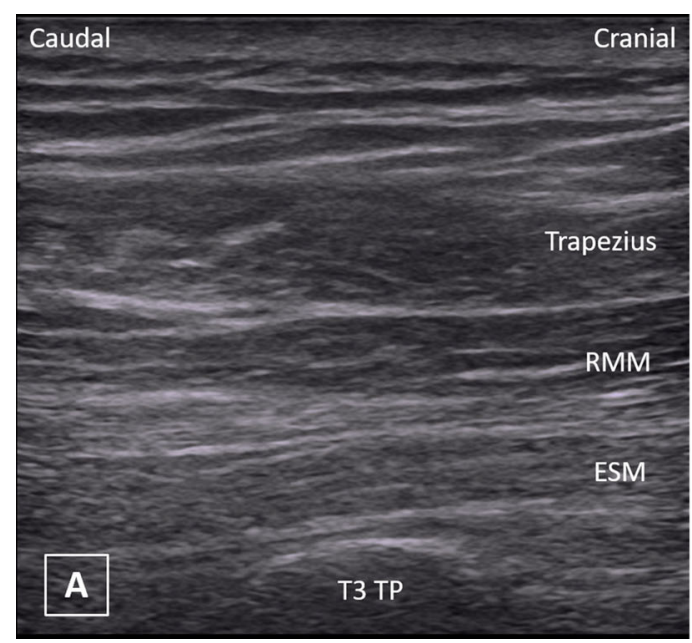

Fig. 1 A) Pre-injection longitudinal parasagittal view of the tip of the $\mathrm{T} 3$ transverse process (TP) and overlying layers of erector spinae muscle (ESM), rhomboid major muscle (RMM), and trapezius. B) Post-injection view showing linear spread of local anesthetic (LA) in

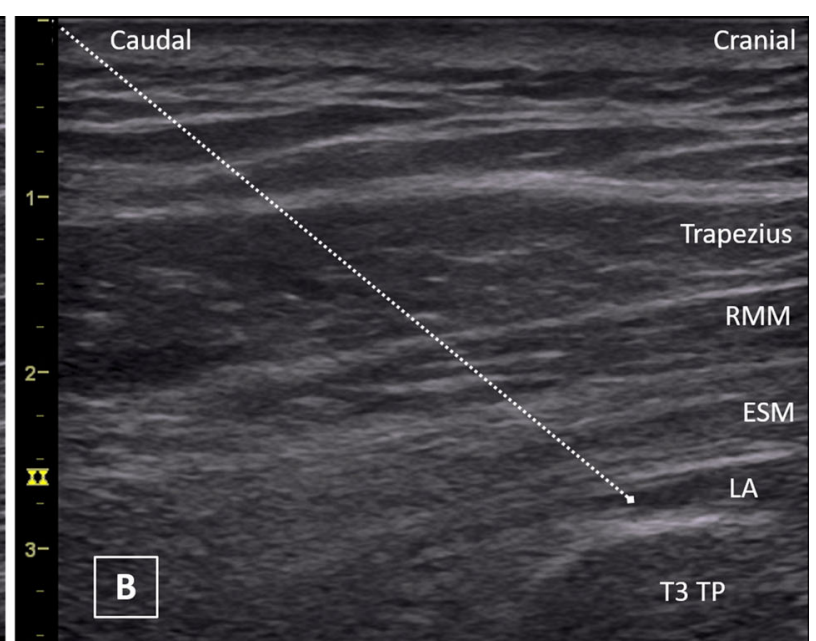

the musculofascial plane between erector spinae muscle and transverse process. The needle trajectory is illustrated by the dotted line 
cape of the shoulder (distribution supplied by the superficial cervical plexus), posterior and anterolateral thorax (T1-T5 dermatomes), and axilla (Fig. 2). There was also noticeable numbness and diminished pinprick sensation in the palmar aspect of his third to fifth digits and thumb. There was no clinically apparent motor blockade of the left upper limb (relative to the contralateral side) on testing of abduction-adduction at the shoulder, flexion-extension at the elbow and wrist, and hand-grip strength.

At follow-up 12 weeks later, the patient reported his left shoulder remained painfree at rest with only mild pain (2/ 10) on movement. However, he complained of recurrent severe (9/10) right shoulder pain on abduction and anterior flexion. He requested an ESP block instead of the previous subdeltoid bursa injections, and this was performed on the right side at the $\mathrm{T} 3$ vertebral level as described above with $20 \mathrm{~mL}$ of $0.375 \%$ bupivacaine, epinephrine $5 \mu \mathrm{g} \cdot \mathrm{mL}^{-1}$, and $40 \mathrm{mg}$ of methylprednisolone. Forty-five minutes after the block, he was able to fully flex and abduct his shoulder with only mild (1-2/10) discomfort. He returned for assessment one week later, at which time he still had good range of motion and only mild (2/10) dynamic pain. He expressed a desire to prolong and, if possible, improve this level of analgesia; a right ESP block was therefore repeated with $20 \mathrm{~mL}$ of $0.375 \%$ bupivacaine and epinephrine $5 \mu \mathrm{g} \cdot \mathrm{mL}^{-1}$, which produced complete pain relief within ten minutes.

At follow-up six weeks later, the patient reported having had excellent analgesia for two weeks, following which his right shoulder pain had gradually recurred, peaking at $8 / 10$
NRS-severity with attempted abduction beyond $90^{\circ}$. His left shoulder remained pain free at rest with only mild (2/ 10) pain on movement. A third ESP block was performed on the right side at $\mathrm{T} 3$ with $20 \mathrm{~mL}$ of $0.25 \%$ ropivacaine, epinephrine $5 \mu \mathrm{g} \cdot \mathrm{mL}^{-1}$, and $40 \mathrm{mg}$ of methylprednisolone, which again rapidly produced complete analgesia and restored normal range of motion.

At the next follow-up six weeks later, the patient reported a similar pattern of good analgesia in his right shoulder for three weeks followed by gradual recurrence of pain on abduction. We obtained consent to repeat the ESP block, but also to perform radiocontrast dye injection and a computed tomography (CT) scan of his right shoulder to characterize the spread of the injectate. The ESP block was performed at T2, this time with $20 \mathrm{~mL}$ of a mixture of $5 \mathrm{~mL}$ of Omnipaque ${ }^{\mathrm{TM}}$ (GE Healthcare Ireland, Cork, Ireland) (iohexol) $300 \mathrm{mg} \cdot \mathrm{mL}^{-1}, 14 \mathrm{~mL}$ of $0.5 \%$ ropivacaine with epinephrine $5 \mu \mathrm{g} \cdot \mathrm{mL}^{-1}$, and $40 \mathrm{mg}$ of methylprednisolone, resulting in complete analgesia as before. The CT imaging two hours after injection showed radiocontrast tracking from T3 up to $\mathrm{C} 3$ and dispersing within the erector spinae muscle (Fig. 3). There was also visible anterior spread of contrast in the plane between the erector spinae and levator scapulae muscles into the vicinity of the neural foramina at C4-C7 (Fig. 4).

At the most recent follow-up by telephone two weeks later, the patient reported that the pain in his right shoulder on movement remained controlled at 2-3/10 and that his left shoulder was asymptomatic.

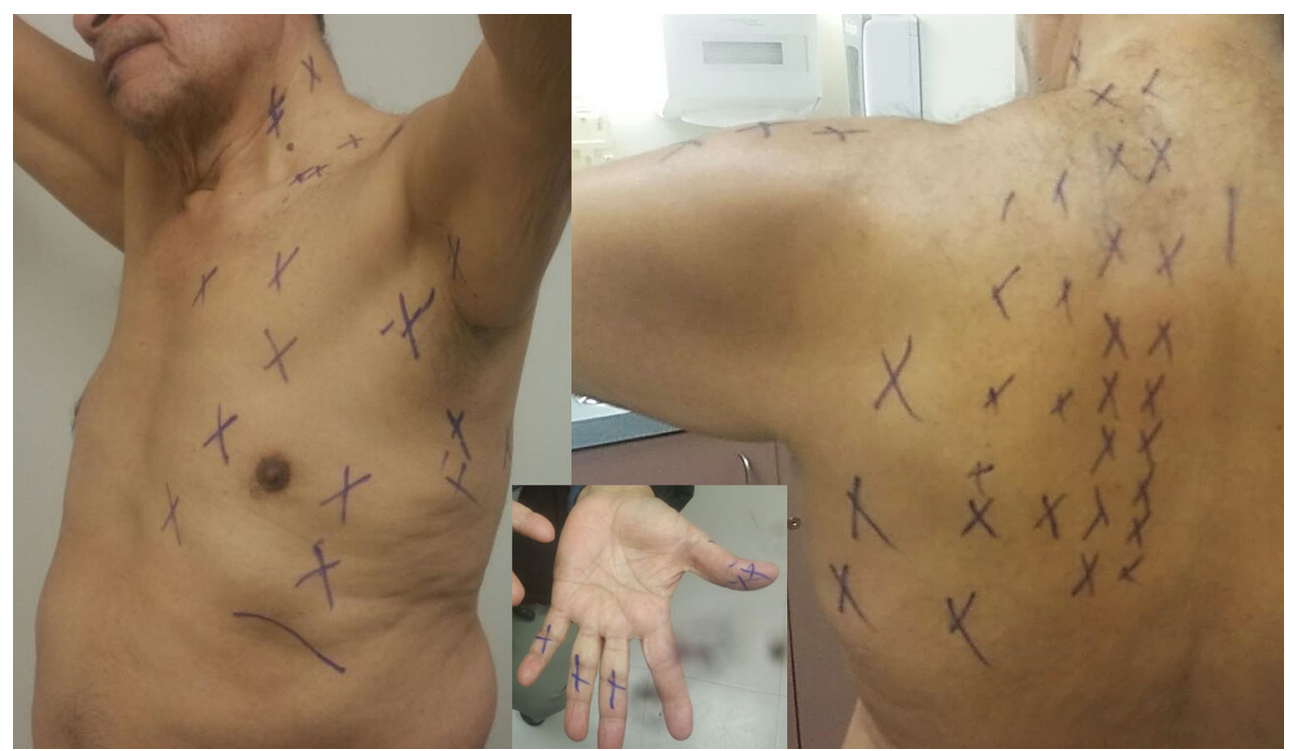

Fig. 2 Distribution of diminished pinprick sensation after an erector spinae plane block injection at the T3 transverse process with $20 \mathrm{~mL}$ of local anesthetic 

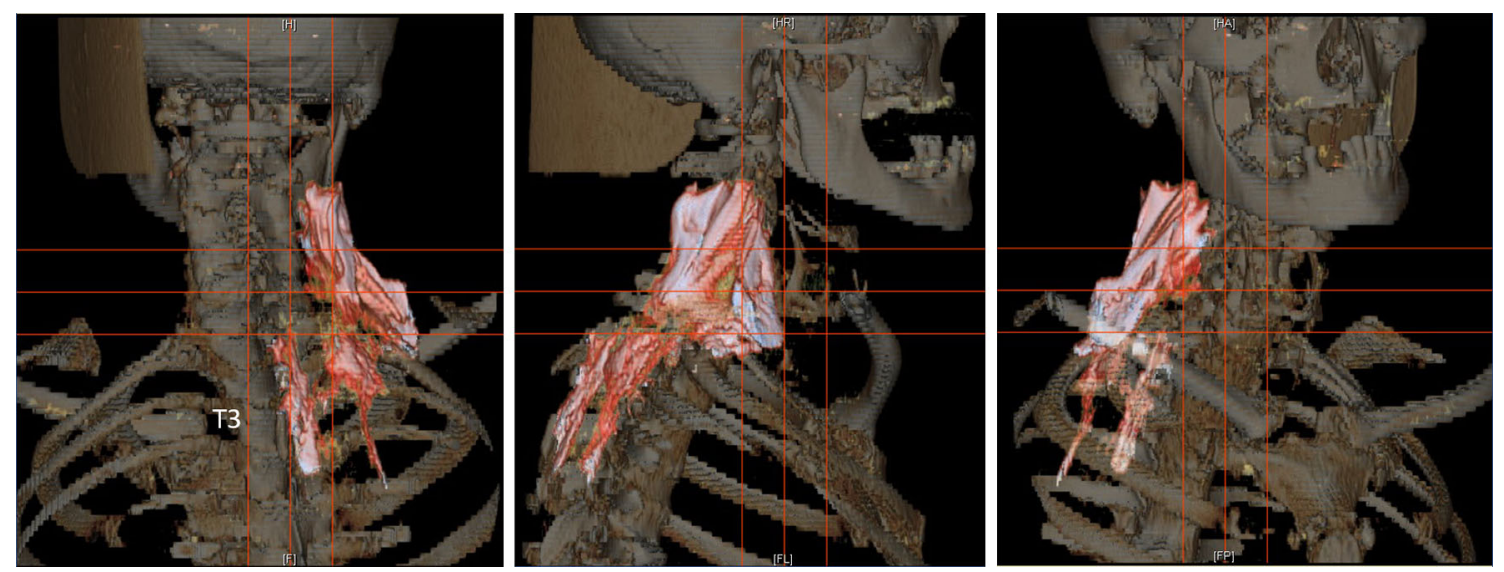

Fig. 3 Three-dimensional computed tomography reconstruction of injectate spread after a right erector spinae plane block at the T2 transverse process with $20 \mathrm{~mL}$. Contrast has tracked cranially to the upper cervical vertebral levels as well as anterolaterally

\section{Discussion}

Chronic shoulder pain often results from a combination of post-traumatic, inflammatory, and degenerative changes in the various muscles, tendons, ligaments, and joints that constitute the shoulder girdle. Some of the structural pathologies are amenable to surgical treatment but the proportion tends to be small. ${ }^{10}$ In most situations oral analgesics and physiotherapy remain the mainstay of management. Targeted US-guided interventions have also become popular for symptomatic relief. Local anesthetic and corticosteroid are injected either directly into the affected musculoskeletal structure (tendon, joint, or bursa) or around the nerves supplying the shoulder joint and girdle. $^{2,3}$ This latter strategy may be preferable where characteristics of neuropathic pain are present, as well as to avoid concerns of chondrotoxicity from repeated intraarticular injections. ${ }^{11,12}$

The ESP block was originally described for management of thoracic pain with injection at the T5 transverse process. ${ }^{4-6}$ Its therapeutic effect is attributed to the cranial-caudal spread of local anesthetic over multiple vertebral levels in the musculofascial plane deep to the erector spinae muscle, accompanied by diffusion anteriorly into the contiguous paravertebral and intercostal spaces, where the local anesthetic then acts on the ventral and dorsal rami of spinal nerves. The subsequent realization that the erector spinae muscle extends from the lumbar spine to cervical spine led to extrapolation of the ESP block for abdominal analgesia by injecting at the lower transverse processes (T7-T10) ${ }^{7-9}$ and now, as described here, shoulder analgesia by injecting at the higher level of $\mathrm{T} 2$ or T3. The cervical portion of the three separate muscles that constitute the erector spinae muscle (semispinalis cervicis, longissimus cervicis, and iliocostalis cervicis) insert onto the transverse processes of the C2-C6 vertebrae and thus provide a pathway for cranial spread of injected fluid as demonstrated on CT imaging. Computed tomography imaging also indicates that the injectate diffuses anteriorly through the erector spinae muscle and over its surface, in the plane created by the adjacent levator scapulae muscle, to reach the vicinity of the cervical neural foramina and exiting nerve roots, where the local anesthetic presumably exerts its effect. This would explain the pain relief as well as the pattern of sensory block that was observed.

The absence of an apparent motor block despite the analgesia that was obtained is also remarkable. The explanation may lie in the differential effect of local anesthetics on different nerve fibres, combined with the fact that our radiological findings indicate only a small proportion of the local anesthetic injected in an ESP block at $\mathrm{T} 2$ reaches the cervical nerve roots. In vitro studies have shown that the larger myelinated A fibres (responsible for motor conduction) are more sensitive to local anesthetics compared to the unmyelinated $\mathrm{C}$ fibres (primarily responsible for nociception). ${ }^{13,14}$ However, this is only true when local anesthetic is applied to the nerve at high concentrations and when an equilibrium level of block has been achieved. When intact nerves are exposed to local anesthetics with a high pKa (e.g., bupivacaine and ropivacaine) at lower concentrations, $\mathrm{C}$ fibres are consistently blocked ahead of A fibres. ${ }^{13-15}$ The high pKa decreases the rate at which local anesthetic can penetrate the myelin sheath of A fibres, and at low concentrations, reabsorption and redistribution may prevent sufficient quantities of the drug from reaching the axonal membrane and inducing significant blockade. This has been postulated as the reason for the commonly observed ability of bupivacaine and ropivacaine to provide analgesia with minimal motor block. ${ }^{13}$ 

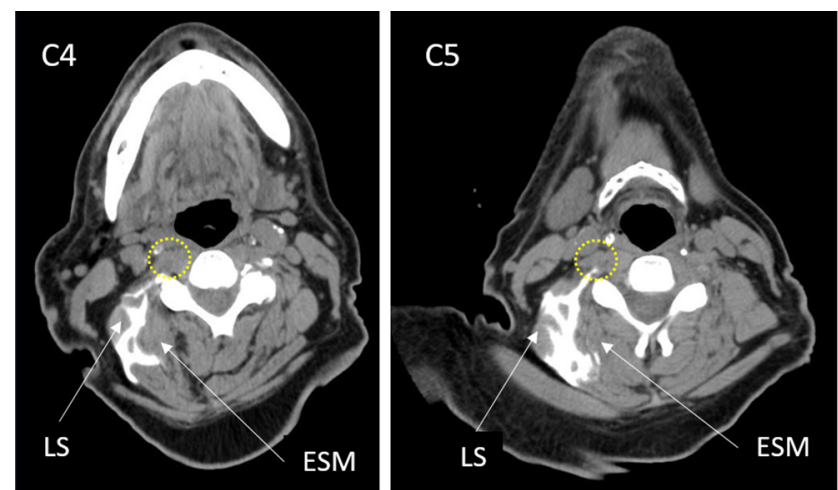

Fig. 4 Axial computed tomography scans at the C4-C7 vertebral levels following a right erector spinae plane block at the $\mathrm{T} 2$ transverse process with $20 \mathrm{~mL}$. Contrast (white areas) has dispersed cranially through erector spinae muscle (ESM) and spread anteriorly between

Our patient consistently experienced profound pain relief and significant improvement in active range of motion following the ESP block. As might be expected given the fixed duration of action of local anesthetics, the profound analgesia was temporary but nevertheless proved valuable in interrupting the pain cycle, which in turn allowed resumption of physical therapy, and optimization of systemic analgesia, all of which are important elements in the overall management of chronic musculoskeletal pain. The ability of local anesthetic nerve blocks to provide analgesic benefit well beyond the expected duration of conduction blockade has been previously confirmed in a recent meta-analysis of suprascapular nerve block in the setting of chronic shoulder pain. ${ }^{16}$

If the ESP block at $\mathrm{T} 2$ or $\mathrm{T} 3$ does indeed exert its effect via blockade of the $\mathrm{C} 5$ and $\mathrm{C} 6$ nerve roots, it should block not only the suprascapular nerve, but also the axillary and lateral pectoral nerves. It may therefore be potentially more effective than an isolated suprascapular nerve block, especially in chronic shoulder pain originating from multiple sources. In addition, the ESP block is technically straightforward, can be performed in the clinic setting, and is relatively safe since injection occurs well away from the neuraxis and lung. The most significant risk with the ESP block, in our experience, is local anesthetic systemic toxicity due to systemic absorption. We currently routinely add epinephrine to the local anesthetic (including ropivacaine), ${ }^{17}$ observe maximum recommended local anesthetic dose limits, have $20 \%$ lipid emulsion readily available, and monitor the patient for at least one hour after the block. ${ }^{18} \mathrm{An}$ additional consideration in this instance, given the observed spread in the vicinity of cervical nerve roots, is that of possible hemidiaphragmatic paresis. We have not observed any episodes of hypoxemia or dyspnea to date but practitioners should remain vigilant.
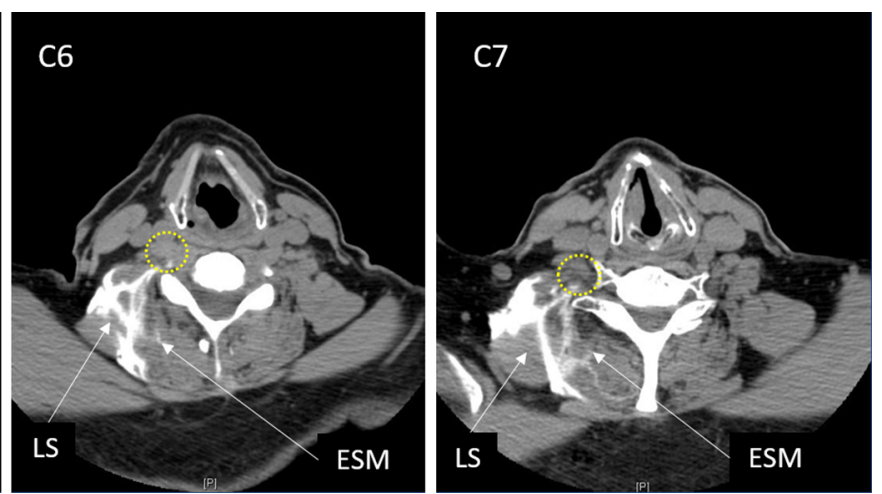

ESM and levator scapulae (LS) muscle into the immediate vicinity of the neural foramina and spinal nerve roots (location indicated by dotted circle)

We have since managed several other patients in a similar fashion and our early experience indicates that an ESP block performed at the T2 level is effective in relieving chronic shoulder pain. Further investigation is needed to establish its long-term efficacy and to determine how it compares with other techniques such as the suprascapular nerve block.

\section{Conflicts of interest None declared.}

Editorial responsibility This submission was handled by Dr. Hilary P. Grocott, Editor-in-Chief, Canadian Journal of Anesthesia.

Author contributions Mauricio Forero and Manikandan Rajarathinam contributed to the clinical conduct of the study, data collection, and writing of the manuscript. Sanjib Das Adhikary contributed to analysis and interpretation of the collected data and writing of the manuscript. Ki Jinn Chin contributed to analysis and interpretation of the collected data, writing, preparation of accompanying figures and material, and revision of the manuscript.

Funding This work received no specific funding from any sources. Dr. Ki Jinn Chin is supported by a Merit Award from the Department of Anesthesia, University of Toronto.

\section{References}

1. Kuijpers T, van der Windt DA, van der Heijden GJ, Bouter LM. Systematic review of prognostic cohort studies on shoulder disorders. Pain 2004; 109: 420-31.

2. Peng $P W$, Cheng $P$. Ultrasound-guided interventional procedures in pain medicine: a review of anatomy, sonoanatomy, and procedures. Part III: shoulder. Reg Anesth Pain Med 2011; 36: 592-605.

3. Pourcho AM, Colio SW, Hall MM. Ultrasound-guided interventional procedures about the shoulder: anatomy, indications, and techniques. Phys Med Rehabil Clin N Am 2016; 27: 555-72. 
4. Forero M, Adhikary SD, Lopez H, Tsui C, Chin KJ. The erector spinae plane block: a novel analgesic technique in thoracic neuropathic pain. Reg Anesth Pain Med 2016; 41: 621-7.

5. Forero M, Rajarathinam M, Adhikary S, Chin KJ. Erector spinae plane (ESP) block in the management of post thoracotomy pain syndrome: a case series. Scand J Pain 2017. DOI: https://doi.org/ 10.1016/j.sjpain.2017.08.013.

6. Muñoz F, Cubillos J, Bonilla AJ, Chin KJ. Erector spinae plane block for postoperative analgesia in pediatric oncological thoracic surgery. Can J Anesth 2017; 64: 880-2.

7. Chin KJ, Malhas L, Perlas A. The erector spinae plane block provides visceral abdominal analgesia in bariatric surgery: a report of 3 cases. Reg Anesth Pain Med 2017; 42: 372-6.

8. Chin KJ, Adhikary S, Sarwani N, Forero M. The analgesic efficacy of pre-operative bilateral erector spinae plane (ESP) blocks in patients having ventral hernia repair. Anaesthesia 2017; 72: 452-60.

9. Restrepo-Garces CE, Chin KJ, Suarez P, Diaz A. Bilateral continuous erector spinae plane block contributes to effective postoperative analgesia after major open abdominal surgery: a case report. AA Case Rep 2017. DOI: https://doi.org/10.1213/ XAA.0000000000000605.

10. Chaudhury S, Gwilym SE, Moser J, Carr AJ. Surgical options for patients with shoulder pain. Nat Rev Rheumatol 2010; 6: 217-26.

11. Sherman SL, Khazai RS, James CH, Stoker AM, Flood DL, Cook $J L$. In vitro toxicity of local anesthetics and corticosteroids on chondrocyte and synoviocyte viability and metabolism. Cartilage 2015; 6: 233-40.
12. Wernecke C, Braun HJ, Dragoo JL. The effect of intra-articular corticosteroids on articular cartilage: a systematic review. Orthop J Sports Med 2015. DOI: https://doi.org/10.1177/ 2325967115581163.

13. Wildsmith JA, Brown DT, Paul D, Johnson S. Structure-activity relationships in differential nerve block at high and low frequency stimulation. Br J Anaesth 1989; 63: 444-52.

14. Gissen AJ, Covino BG, Gregus J. Differential sensitivity of fast and slow fibers in mammalian nerve. III. Effect of etidocaine and bupivacaine on fast/slow fibers. Anesth Analg 1982; 61: 570-5.

15. Ford DJ, Raj PP, Singh P, Regan KM, Ohlweiler D. Differential peripheral nerve block by local anesthetics in the cat. Anesthesiology 1984; 60: 28-33.

16. Chang $K V$, Hung $C Y, W u W T$, Han DS, Yang RS, Lin $C P$. Comparison of the effectiveness of suprascapular nerve block with physical therapy, placebo, and intra-articular injection in management of chronic shoulder pain: a meta-analysis of randomized controlled trials. Arch Phys Med Rehabil 2016; 97 : 1366-80.

17. Kitayama M, Wada M, Hashimoto H, Kudo T, Takada N, Hirota $K$. Effects of adding epinephrine on the early systemic absorption kinetics of local anesthetics in abdominal truncal blocks. J Anesth 2014; 28: 631-4.

18. El-Boghdadly $K$, Chin KJ. Local anesthetic systemic toxicity: continuing professional development. Can J Anesth 2016; 63: $330-49$. 